\title{
Complications of Polymers on Drug-eluting Stents: Looking Toward Polymer-free Drug-eluting Stents
}

\author{
Jiro Aoki
}

Key words: polymer, stent, embolization

(Intern Med 54: 549-550, 2015)

(DOI: 10.2169/internalmedicine.54.3855)

Drug-eluting stents (DES) are generally used as the first choice of coronary stents in the field of interventional cardiology. DES are composed of a metallic platform (the stent), a polymer coating and an antiproliferative drug to prevent in-stent restenosis. The development of a suitable polymer has been challenging, since it must have mechanical resistance to abrasion during the procedure, be suitable for sterilization, allow time- and dose controlled drug release, while decreasing local inflammatory reactions and thrombosis $(1,2)$. Various polymer coatings have been developed, and biocompatible polymers are currently used as DES components. Nonetheless, concerns about the complications of polymers have arisen in daily clinical practice.

In the first generation DES era, a hypersensitivity reaction limited to the coronary artery wall surrounding the stent was reported. This hypersensitive vasculitis caused lifethreatening stent thrombosis which potentially occurred after more than one year after implantation, leading to so-called "late stent thrombosis" (3). To improve the safety profile of DES, second generation DES have been developed. The new polymers are more biocompatible, with a thinner and more uniform layer and yield a reduced eluted drug dose compared to the previous polymer. As a result, the second generation DES are associated with a lower risk of in-stent restenosis and stent thrombosis compared to the first generation DES (4). However, a recent pathological study indicated that the newer generation durable polymers are still a source of inflammation, neoatherosclerosis and thrombosis risk (5). Interventional cardiologists prudently take account of this phenomenon.

In this issue of the journal, Fujisaka et al, report the intracoronary embolization of coating polymers, and describe which might cause fatal myocardial infarction (6). Myocardial infarction due to polymer embolization theoretically occurs in patients with tortuous and/or calcified coronary lesions. However, there have been few reports to show whether the damage to the polymer in a DES can cause polymer embolization in cases undergoing complex procedures (7-10). Therefore, this complication has not been highlighted so far. Fujisaka and co-authors sound the alarm this rare but potentially life-threatening complication of DES. Several approaches can prevent this complication. In terms of the procedural factors, stent delivery by the mother and child method using a 4 Fr strait-guide catheter, and rotational atherectomy prior to stent delivery, are effective for reducing polymer damage.

Ultimately, the use of polymer-free DES would prevent polymer embolization during the procedure. However, the development of polymer-free DES is technically challenging, since such DES would need to be able to elute antiproliferative drugs in a controlled manner in the absence of a polymer. This can now achieved by 1) dissolving the drug into a nonpolymeric biodegradable carrier, such as hydroxyapatite, on the stent's surface, 2) impregnating the drug onto the nano-size porous surface of the stent, 3) attaching the drug directly to the stent surface using either covalent bonding or crystallization/chemical precipitation and 4) filling the drug into a hollow core inside the stent strut $(11,12)$. Several concepts for polymer-free DES have already been developed and clinically tested outside Japan, and fully bioabsorbable drug-eluting vascular scaffolds are now available for clinical use outside Japan (13). It remains to be determined whether these devices are safe and effective compared to metal DES. Distal embolization similar to this case might still occur in patients treated using fully bioabsorbable drug-eluting vascular scaffolds.

The author states that he has no Conflict of Interest (COI).

\section{References}

1. Serruys PW, Kutryk MJ, Ong AT. Coronary-artery stents. N Engl J 
Med 354: 483-495, 2006.

2. Stefanini GG, Holmes DR Jr. Drug-eluting coronary-artery stents. N Engl J Med 368: 254-265, 2013.

3. Virmani R, Guagliumi G, Farb A, et al. Localized hypersensitivity and late coronary thrombosis secondary to a sirolimus-eluting stent: should we be cautious? Circulation 109: 701-705, 2004.

4. Navarese EP, Tandjung K, Claessen B, et al. Safety and efficacy outcomes of first and second generation durable polymer drug eluting stents and biodegradable polymer biolimus eluting stents in clinical practice: comprehensive network meta-analysis. BMJ 347: f6530, 2013.

5. Otsuka F, Vorpahl M, Nakano M, et al. Pathology of secondgeneration everolimus-eluting stents versus first-generation sirolimus- and paclitaxel-eluting stents in humans. Circulation 129: 211-223, 2014.

6. Fujisaka T, Miyamura M, Satomi H, Ishizaka N. Intracoronary embolization of the coating polymer on a cardiovascular device. Intern Med 54: 679-680, 2015.

7. Kuriyama N, Kobayashi Y, Nakayama T, Kuroda N, Komuro I.
Images in cardiovascular medicine. Damage to polymer of a sirolimus-eluting stent. Circulation 114: e586-e587, 2006.

8. Kitahara H, Kobayashi Y, Yamaguchi M, et al. Damage to polymer of paclitaxel-eluting stent. Circ J 72: 1907-1908, 2008.

9. Kuriyama N, Kobayashi Y, Yamaguchi M, Shibata Y. Usefulness of rotational atherectomy in preventing polymer damage of everolimus-eluting stent in calcified coronary artery. JACC Cardiovasc Interv 4: 588-589, 2011.

10. Fujimoto Y, Kobayashi Y, Yamaguchi M. Delamination of abluminal polymer of biolimus-eluting stent. JACC Cardiovasc Interv 5: e5-e6, 2012.

11. Abizaid A, Costa JR Jr. New drug-eluting stents: an overview on biodegradable and polymer-free next-generation stent systems. Circ Cardiovasc Interv 3: 384-393, 2010.

12. Garg S, Serruys PW. Coronary stents: looking forward. J Am Coll Cardiol 56: S43-S78, 2010.

13. Iqbal J, Onuma Y, Ormiston J, Abizaid A, Waksman R, Serruys P. Bioresorbable scaffolds: rationale, current status, challenges, and future. Eur Heart J 35: 765-776, 2014.

(C) 2015 The Japanese Society of Internal Medicine http://www.naika.or.jp/imonline/index.html 